\title{
Characterization of Inferior alveolar Canal in Sudanese population using orthopantomography
}

\author{
Caroline Edward Ayad ${ }^{1, ~ *}$, Zenab Homeda Ali Elhag ${ }^{1}$, Elsafi Ahmed Abdalla ${ }^{1}$, \\ Mohammed Elfadil Mohammed ${ }^{1}$, Samih Kajoak ${ }^{2}$ \\ ${ }^{1}$ Diagnostic Radiology Department, College of Medical Radiological Science, Sudan University of Science and Technology, Khartoum , \\ Sudan \\ ${ }^{2}$ College of Applied Medical Sciences, Diagnostic Radiology Department, Hail University, Saudi Arabia
}

\section{Email address:}

carolineayad@yahoo.com (C. E. Ayad),Zenabhomeda@yahoo.com (Z. H. A. Elhag), dr.Elsafi@gmail.com (E. A. Abdalla), mohamedelfadil@yahoo.com (M. E. Mohammed),Samihawad@yahoo.com (S. Kajoak)

\section{To cite this article:}

Caroline Edward Ayad, Zenab Homeda Ali Elhag, Elsafi Ahmed Abdalla, Mohammed Elfadil Mohammed, Samih Kajoak. Characterization of Inferior Alveolar Canal in Sudanese Populations Using Orthopantomography. International Journal of Medical Imaging. Vol. 1, No. 3, 2013, pp. 39-44. doi: 10.11648/j.ijmi.20130103.11

\begin{abstract}
The importance of Inferior alveolar Canal lies in that it may be positioned at different locations in the mandible, where the mandibular nerve bundle passes through and may be damaged during dental implantation. The researchers characterized the Inferior alveolar Canal in order to avoid injury during the maxillofacial surgery or during dental implant procedures in both sides of the mandible and in both genders and compared the variables in the Sudanese population with those reported in other nations. The study consisted of two hundred and two Orthopantomograms which were collected and analyzed; five measures were selected and studied for right and left sides of the jaw for males and females. The distances were measured in millimeters: distance between superior border of Inferior alveolar Canal and second molar, second premolar and alveolar bone, height of Inferior alveolar Canal and the distance to the mandible border. The collected data were then correlated with age and gender. The results showed that the measured distances were correlated linearly with age in both genders, and no significant differences were detected when comparing both sides of the mandibles in both genders. Significant differences between males and females measurements were detected and also in the Sudanese and other populations. The research has come out with findings that Orthopantomogram is suitable radiological method to characterize the location of Inferior alveolar Canal for Sudanese population as the knowledge about the canal anatomical variations is essential in order to avoid complications during dental surgery or treatment.
\end{abstract}

Keywords: Inferior Alveolar Canal, Nerves, Anatomy, Orthopantomography

\section{Introduction}

The mandibuler canal (MC) is a canal within the mandible starting in mandibular foramen .It runs obliquely downward and forward in the ramus, and then horizontally forward in the body. It carries inferior alveolar neurovascular bundle [1].

Different anatomical variation may happened in $\mathrm{MC}$ as to be bifid or trifid resulted from embryological development errors.[2]

It was reported that $\mathrm{MC}$ might have different anatomic configurations in the horizontal plane, the $\mathrm{MC}$ crosses from the lingual to the buccal side of the mandible or the midway between the bucal and lingual cortical plates of bone by the first molar [3, 4].Difference may exist in the vertical plane [2] The vertical position of the MC was evaluated using either root apices of mandibular teeth and inferior border of mandible as anatomical landmark.[2]

The radiographic examination for detecting mandible canal is periapical, orthopantomography and CT scan [5], panoramic radiography in comparison with computed tomography $\mathrm{CT}$, has been found to be sufficiently accurate in measuring the vertical bone depth of the mandible [6].Many characteristics changes may happen due to race and age and were statistically associated with MC position relate to the buccal cortical mandibular margin. The buccolingual location of the MC is classified into 3 types: type $1(70 \%)$, where the canal follows the lingual cortical plate at the mandibular ramus and body; type $2(15 \%)$, where the canal follows the middle of the ramus behind the 
second molar and the lingual plate passing through the second and first molars; and type $3(15 \%)$, where the canal follows the middle or the lingual one third of the mandible from the ramus to the body. [7]

Damage to mandible nerves bundles is often arising from surgical mistakes during dental implants as well as fails to identify these structures [8]. Determination of the location and configuration of the mandibular canal (MC) and related anatomical structures is critical so as to minimize the risk of damage [9].

Most of the published data were for Asian population or done for cadavers, the knowledge about the anatomical variation will help in the avoidance of being injured during surgery; in Sudan, as far as we know, no study was published in the open literature regarding the characterization and measurement of mandibular canal in Sudanese populations.

\section{Objectives}

The study aimed to characterize the mandibuler canal which is an important anatomical structure in the mandible for Sudanese who were selected as one of the African populations and to compare the findings with other populations using simple radiological method.

\section{Materials and Methods}

The study was done at Mursi Medical Center- Khartoum -Sudan during the period from March 2011 to August 2011.OPG machine GENDEX was used by applying $47 \mathrm{Kv}$, $10 \mathrm{mAs}$. All foreign objects, including dental appliances, spectacles and earrings were removed. The patient's head was positioned and the correct position relative to the focal trough was achieved by having the incisors resting in a radiolucent notched positioning device, the bite block. All patients rested the tongue against the palate. Dental panoramic tomography was carried out with intensifying screens to limit the radiation dose. The occlusal plane was tilted 20-30degrees antero-inferiorly, achieved by placing the head so that a line from the tragus to the outer canthus is horizontal[10] .202 OPGs were collected and analyzed, five measures were selected and studied for right and left sides of the jaw for males and females. The distances were measured using computer soft ware programme and were defined as follows, and were measured in millimeters:

$\mathrm{D} 1=$ distance between superior border of $\mathrm{MC}$ and $2 \mathrm{nd}$ molar, D2 = distance between superior border of $\mathrm{MC}$ and 2nd premolar, D3= distance from superior border of $\mathrm{MC}$ to alveolar bone.D4= height of $\mathrm{MC}, \mathrm{D} 5=$ distance between MC to mandible border.

The data were analyzed using SPSS program version 16 Independent $\mathrm{T}$ - test, simple tables including frequency and percentages, and $p$-value for testing the results significances of the variables was used; $P$ value is significant when $<0.005$.

\section{Results}

This study included 202 dental panoramic films for both genders (101males and101 females), the films were used to collect the data. Their mean ages and standard deviation (SD) were $32.17 \pm 8.48$.The results were presented in tables and figures.

\section{Discussion}

Knowledge of the anatomy of the inferior alveolar canal and its location is of great importance to the oral and maxilla facial surgeon. Researches had done to study the anatomy including location, shape and course of the inferior alveolar canal with different radiographic methods including conventional CT scan as well as morphological studies in cadavers.

The main objectives of this study were to evaluate and assess the localization of IAC using OPG as a routine method used in dentistry.

The researchers used five variables including (D1, D2, D3, D4 and D5) in both mandible sides and in both gender (males and females) to localize the inferior alveolar canal which is important in many surgical procedures where the nerve paths though and may be affected during dental implants, which was a critical point during surgery.

Values of the variables for total sample measurements of the right and left sides were presented in table[1]; the average of the variables means from D1toD5 were presented in tables[2,3], they were for females and males in respectively.

D1 was found to be $(5.2,7.4)$ whereD2was found to be(8.6,9.7),D3(11.9,15.3)D4(2.4,3.1)and D5(8.96,10.6)

The study showed that no significant difference was detected between RT and LT sides of the mandible and no significant relationship between the variables with gender $P$. value $(0.005)$ as presented in table [4]

The changes of the variables measurements according to age in both genders were noticed due to the noticeable linear association between the variables and were presented in table [5]

Using the linear regression method for variables, the correlations were presented in the figures [1-4].

Scatter plot of the D1, D2 and D3 values resume the ages of the 101 female and 101 males with a trend line showing the linear association between the variables that were described by the linear equations, it showed that as the ages increased the measurements were also increased, this was presented in the figures $[1,3]$.

Figures $[2,4]$ showed the same linear association between the variables including D4 and D5 with females and males ages.

An equation to show the linear relation should be applied to know the resultant measurements associated with age (measurement in $\mathrm{mm} /$ year),eg:

Distance $=$ Linear coefficient $\mathrm{X}$ age + constant Eq. 1

The results showed that there were significant difference 
detected when measuring D1, D2, D 3, and D5 in males and females, but no significant relationship was found in D4 at $p$. value of 0.005 .The study findings were similar to other Asian populations for the measurements done for the variables except D1 and D2; it was found that the Asians have larger measurements than Sudanese populations as noticed in table [6] .

The age is an important factor that can affected the measurements as it was detected in the above mentioned figures where the measurements increased by increasing of the sample age, adverse suggestions were mentioned by Gintaras Juodzbalys[2] in his study about the anatomical variations and position of the mandible canal ,he mentioned that age and race were statistically associated with MC position relate to the buccal cortical mandibular margin $(\mathrm{P}<0.05)$. Older patients and white patients, on average, have less distance between the buccal aspect of the canal and the buccal mandibular border, but this phrase consigned with our results as mentioned in figure (2) in the female readings. The reduction of D4 in females by increasing age may be related to the hormonal disturbance that may happen due to age similar findings and interpretation was found by Gintaras.[2]

\section{Conclusion}

This study is an attempt to localize MC correctly for Sudanese population in order to avoid injury during the maxillofacial surgery or during dental implant procedures, as well as to study and assess the location of the inferior mandibular canal in both sides of the mandible and in both genders. Therefore this study was done to explain the differences in measurements for 101 males and 101 females related to age, using the OPG techniques. The results showed that the D1, D2, D3, D4, D5 as variables were correlated well (linearly) with the age in both gender, and no significant difference were detected when comparing both sides of the mandibles in both genders. Significant differences between males and females measurements were detected and also in the Sudanese and other Asian populations who were selected as anther nation for comparison

Table (1). the mean and standard deviation (SD) of the variables that collected from the 202 patients (101 males and 101 females).

\begin{tabular}{ccc}
\hline Variables & $\begin{array}{l}\text { Measurements of the RT } \\
\text { side of the mandible }\end{array}$ & $\begin{array}{c}\text { Measurements of the LT } \\
\text { side of the mandible }\end{array}$ \\
\hline D1 & $6.30 \pm 2.21$ & $6.31 \pm 2.06$ \\
D2 & $9.18 \pm 2.05$ & $9.09 \pm 1.82$ \\
D3 & $13.50 \pm 4.51$ & $13.62 \pm 4.38$ \\
D4 & $2.75 \pm 1.29$ & $2.7 \pm 1.12$ \\
D5 & $9.65 \pm 3.21$ & $9.91 \pm 2.78$ \\
\hline
\end{tabular}

Table (2). Measurements done for females and presented as means and standard deviations.

\begin{tabular}{llll}
\hline Variables & $\begin{array}{l}\text { Measurements of } \\
\text { the RT side of the } \\
\text { mandible }\end{array}$ & $\begin{array}{l}\text { Measurements of } \\
\text { the LT side of the } \\
\text { mandible }\end{array}$ & $\begin{array}{l}\text { Average of } \\
\text { the means }\end{array}$ \\
\hline D1 & $5.07 \pm 1.47$ & $5.36 \pm 1.83$ & $5.216 \pm 1.65$ \\
D2 & $8.53 \pm 1.51$ & $8.6 \pm 1.42$ & $8.565 \pm 1.465$ \\
D3 & $11.82 \pm 2.9$ & $11.9 \pm 3.07$ & $11.86 \pm 2.988$ \\
D4 & $2.33 \pm 1.04$ & $2.4 \pm 1.09$ & $2.365 \pm 1.055$ \\
D5 & $8.72 \pm 2.72$ & $9.2 \pm 2.5$ & $8.96 \pm 2.61$ \\
\hline
\end{tabular}

Table (3). Measurements done for males and presented as means and standard deviations.

\begin{tabular}{llll}
\hline Variables & $\begin{array}{l}\text { Measurements of } \\
\text { the RT side of the } \\
\text { mandible }\end{array}$ & $\begin{array}{l}\text { Measurements of } \\
\text { the LT side of the } \\
\text { mandible }\end{array}$ & $\begin{array}{l}\text { Average Of } \\
\text { the means }\end{array}$ \\
\hline D1 & $7.52 \pm 1.83$ & $7.27 \pm 1.83$ & $7.395 \pm 1.99$ \\
D2 & $9.82 \pm 2.04$ & $9.61 \pm 2.04$ & $9.715 \pm 2.175$ \\
D3 & $15.18 \pm 4.83$ & $15.32 \pm 4.83$ & $15.25 \pm 5.005$ \\
D4 & $3.17 \pm 1.38$ & $3.04 \pm 1.05$ & $3.105 \pm 1.25$ \\
D5 & $10.85 \pm 3.93$ & $10.67 \pm 2.89$ & $10.625 \pm 3.41$ \\
\hline
\end{tabular}

Table (4). shows the correlation between right and left measurements for both gender at $P$ value is (0.005).

\begin{tabular}{cc}
\hline RT and LT measurements for both gender & P-value \\
\hline RT - D1 - F \& RT - D1 - M & .000 \\
RT - D2 - F \& RT - D2 - M & $.647^{* *}$ \\
RT - D3 - F \& RT - D3 - M & .015 \\
RT - D4 - F \& RT - D4 - M & .001 \\
RT - D5 - F \& RT - D5 - M & .000 \\
LT - D1 - F \& LT - D1 - M & .000 \\
LT - D2 - F \& LT - D2 - M & $.697 * *$ \\
LT - D3 - F \& LT - D3 - M & .002 \\
LT - D4 - F \& RT - D4 - M & .000 \\
\hline LT - D5 - F \& RT - D5 - M & .000 \\
\hline
\end{tabular}

RT stands for Right side, LT, stands for left, F for Female. M for Male.*P. value is $0.005, * *$ means there was no significant relationship between the variables with gender. 
Table (5). the changes of measurements according to age in both genders according to the linear association between the two variables measurements, gender and age.

\begin{tabular}{ccc}
\hline Variables & $\begin{array}{c}\text { Increases of } \\
\text { measurements } \\
(\mathbf{m m} / \text { year) in Female }\end{array}$ & $\begin{array}{c}\text { Increase in } \\
\text { measurements } \\
\text { (mm/year) in Male }\end{array}$ \\
\hline D1 & 0.14 & 0.23 \\
D2 & 0.04 & 0.15 \\
D3 & 0.07 & 0.33 \\
D4 & $-0.03 *$ & 0.07 \\
D5 & 0.11 & 0.4 \\
\hline
\end{tabular}

*D4 is decreased by age.

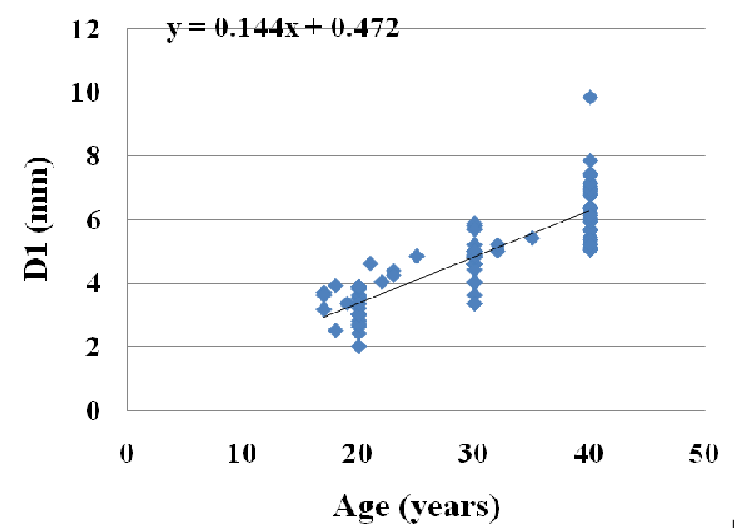

[A]

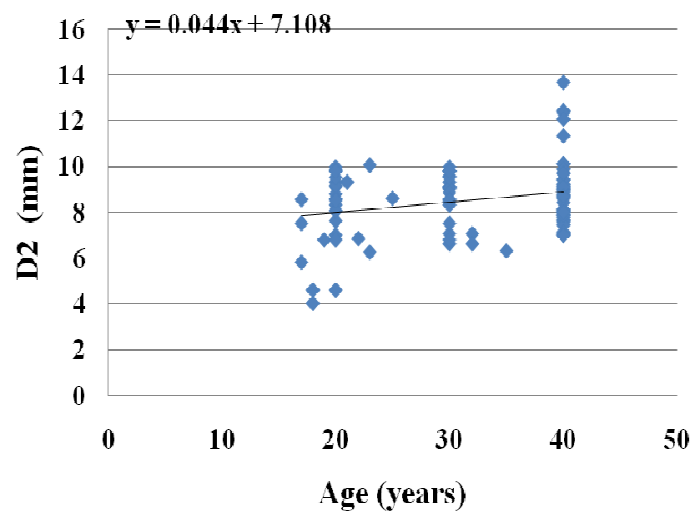

[B]

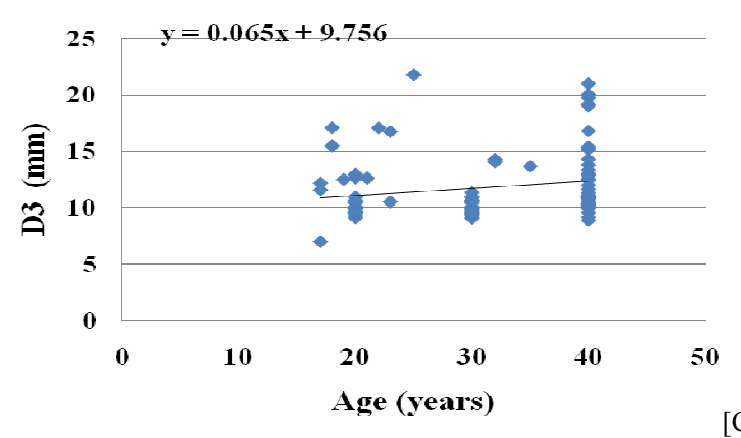

$[\mathrm{C}]$

Figure (1). A,B ,C scatter plot of the D1,D2 and D3 values resume the ages of the 101 female patients with association with a trend line showing the linear association between the two variables that described by the linear equation.

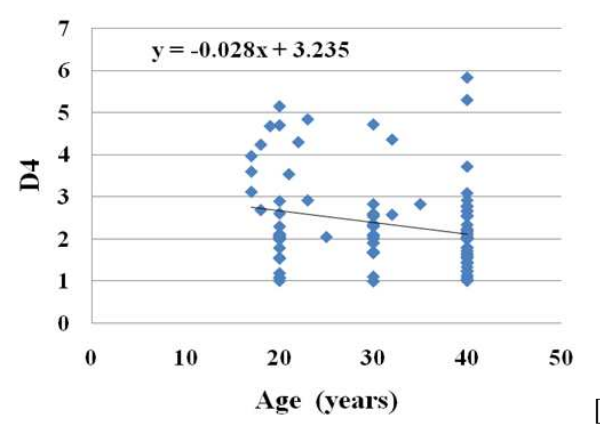

[A]

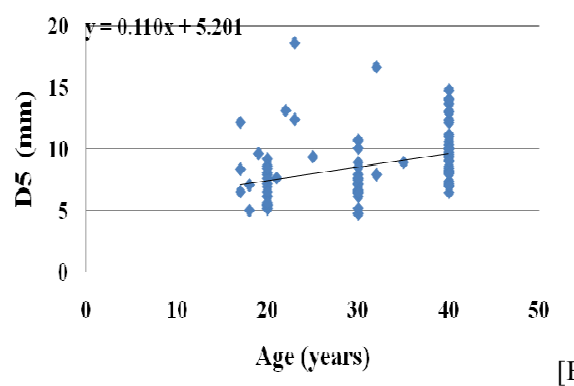

[B]

Figure (2). A,B scatter plot of the D4 and D5values resume the ages of the 101 female patients with association with a trend line showing the linear association between the two variables that described by the linear equation.
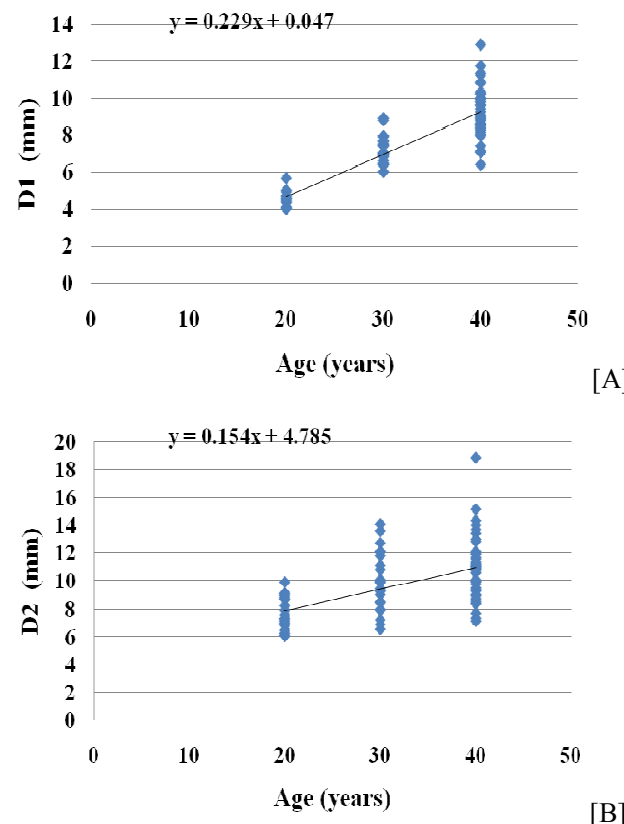

$[\mathrm{B}]$

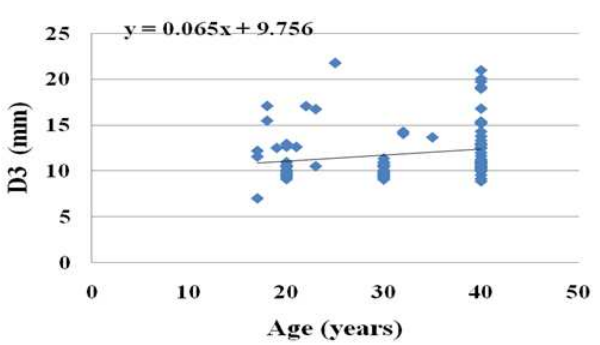

$[\mathrm{C}]$

Figure (3). A,B,C scatter plot of the D1,D2,D3 values resume the age of the 101 male patients with association with a trend line showing the linear association between the two variables that described by the linear equation. 


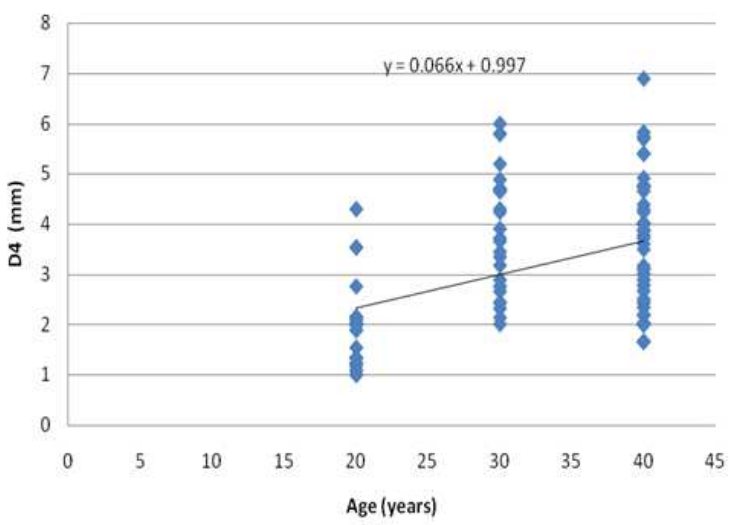

[A]

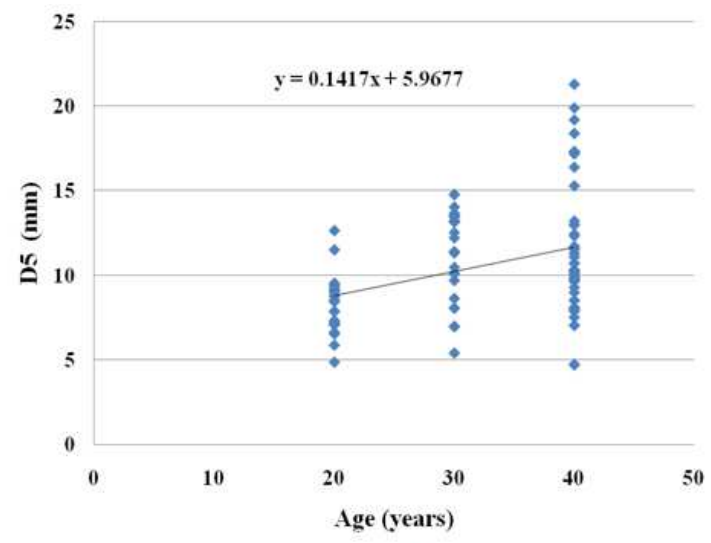

[B]

Figure (4).A,B scatter plot of the D4,D5 values resume the ages of the 101male patients with association with a trend line showing the linear association between the two variables that described by the linear equation.

Table (6). the measurements of the same variables in other populations [Asian (Japanese), Cadavers, African (202 Sudanese: $101 m a l e, 101$ female)

\begin{tabular}{|c|c|c|c|c|}
\hline Variables & Study & Sample & Other populations values & Sudanese populations \\
\hline D4 & Rajchel et al. [11] & 45 Asian adults & $2.0-2.4 \mathrm{~mm}$ in diameter. & $\begin{array}{l}\text { RT2.75 } \pm 1.29 \\
\text { LT2.7 } 2 \text {, } \\
(2.75-2.78)\end{array}$ \\
\hline D4 & Obradovic et al. [12] & 105 cadaver mandibles & $\begin{array}{l}\text { The average diameter of the } \mathrm{MC} \text { in its } \\
\text { horizontal part is } 2.6 \mathrm{~mm} \text {. }\end{array}$ & $(2.75-2.78)$ \\
\hline D4 & Ikeda et al. [13] & cadaver study & Canal width is approximately $3.4 \mathrm{~mm}$. & $(2.75-2.78)$ \\
\hline D4 & Sato et al. [14] & $\begin{array}{l}75 \text { adult Japanese cadavers' } \\
\text { mandibles }\end{array}$ & Vertical diameter of MC was about $5 \mathrm{~mm}$ & $(2.75-2.78)$ \\
\hline D5 & Rajchel et al. [11] & 45 Asian adults & $\begin{array}{l}\text { A mean distance of } 10 \mathrm{~mm} \text { between the } \mathrm{MC} \\
\text { and the inferior mandibular border }\end{array}$ & $\begin{array}{l}\text { Rt9.65 } \pm 3.21 \\
\text { LT9.91 } \pm 2.78 \\
(9.65-9.91)\end{array}$ \\
\hline D1 & $\begin{array}{l}\text { Rajchel et } \\
\text { al\&Obradovic etal. } \\
{[11],[12]}\end{array}$ & 45 Asian adults & $\begin{array}{l}\text { The upper border of the } \mathrm{MC} \text { was located } 3.5 \\
\text { to } 5.4 \mathrm{~mm} \text { below the root apices of the first } \\
\text { and second molars }\end{array}$ & $\begin{array}{l}\text { RT } 6.30 \pm 2.21 \\
\text { LT6.31 } \\
(6.30-6.31)\end{array}$ \\
\hline D1 & Denio et al. [15] & evaluated 22 cadavers & $\begin{array}{l}\text { The mean distance of the MC to the apices } \\
\text { of mandibular second molar, was } 3.7\end{array}$ & $(6.30-6.31)$ \\
\hline D2 & Denio et al. [15] & evaluated 22 cadavers & $\begin{array}{l}\text { The mean distance of the MC to the apices } \\
\text { of mandibular second premolars was } 4.7 \\
\mathrm{~mm}\end{array}$ & $\begin{array}{l}\text { RT } 9.18 \pm 2.06 \\
\text { LT9.1 } \pm 1.83 \\
(9.2-9.1)\end{array}$ \\
\hline D3 & Levine et al. [16] & 50 patients & $\begin{array}{l}\text { The superior aspect of the MC was } 17.4 \mathrm{~mm} \\
\text { inferior from the alveolar crest }\end{array}$ & $\begin{array}{l}\text { RT13.50 } \pm 4.5 \\
\text { LT13.62 } \pm 4.38 \\
(13.5-13.6)\end{array}$ \\
\hline D3 & Watanabe et al. [17] & $\begin{array}{l}\text { Analyzed CT data of } 79 \\
\text { Japanese patients }\end{array}$ & $\begin{array}{l}\text { The distance from the alveolar crest to the } \\
\mathrm{MC} \text { ranged from } 15.3 \text { to } 17.4 \mathrm{~mm}\end{array}$ & $(13.5-13.6)$ \\
\hline
\end{tabular}

\section{References}

[1] T .Tammisalo, RP Happonen, EH Tammisalo. Stereographic assessment of mandibular canal in relation to the roots of impacted lower third molar using multiprojection narrow beam radiography. Int $\mathrm{J}$ Oral Maxillofac Surg. Apr 1992;21(2):85-9

[2] J.Gintaras, W.Hom-Lay, S.Gintautas.Anatomy of Mandibular Vital Structures. Part I: Mandibular Canal and Inferior Alveolar Neurovascular Bundle in Relation with Dental ImplantologyJ Oral Maxillofac Res;2010 (Jan-Mar) vol. 1 ,No 1,3
[3] CS .Miller, PV .Nummikoski, DA Barnett, RP Langlais. Cross-sectional tomography. A diagnostic technique for determining the buccolingual relationship of impacted mandibular third molars and the inferior alveolar neurovascular bundle. Oral Surg Oral Med Oral Pathol. 1990 Dec;70(6):791-7.

[4] H. Davis. Mobilization of the Alveolar Nerve to Allow Placement of Osseointegratible Fixtures. In: Advanced Osseointegration Surgery: Application in the Maxillofacial Region. Chicago: Quintessence Publishing Co.: 2000: 129-141 
[5] C.A Lindh . B,Petersson,Klinge .measurement of distances related to the mandibuler canal in radiographs, Clin Oral Impln Res ,1995;6:96-103

[6] H.Tal \& OA. Moses. comparison of panoramic radiography with computed tomography in planning of implant Surgery.Dentomaxillofacial Radiology,1991; 20:40-42

[7] ST. Kim, KS. Hu, WC. Song, MK. Kang, HD .Park, HJ .Kim. Location of the mandibular canal and the topography of its neurovascular structures. J Craniofac Surg. 2009 May;20(3):936-9.

[8] IS .Kim, SG. Kim, YK. Kim, JD .Kim. Position of the mental foramen in a Korean population: a clinical and radiographic study. Implant Dent. 2006;15(4):404-11.

[9] S. Rueda, JA Gil, R Pichery, M Alcañiz. Automatic segmentation of jaw tissues in CT using active appearance models and semi-automatic landmarking. Med Image Comput Comput Assist Interv. 2006;9:167-74.

[10] AG..Lurie Panoramic imaging. In: White SC, Pharoah MJ (eds). Oral Radiology, 5th edn. Mosby, St Louis, 2004; 191-209

[11] J .Rajchel, Ellis E 3rd, Fonseca RJ. The anatomical location of the mandibular canal: its relationship to the sagittal ramus osteotomy. Int J Adult Orthodon Orthognath Surg. Winter, 1986;1(1):37-47.
[12] O. Obradovic, L .Todorovic, V. Pesic, B .Pejkovic, V.Vitanovic. Morphometric analysis of mandibular canal: clinical aspects. Bull Group Int Rech Sci Stomatol Odontol. 1993 ;36(3-4):109-130

[13] K. Ikeda, KC .Ho, BH. Nowicki, VM .Haughton. Multiplanar MR and anatomic study of the mandibular canal. AJNR Am J Neuroradiol. Mar1996;17(3):579-84.

[14] I .Sato, R. Ueno, T .Kawai, T. Yosue. Rare courses of the mandibular canal in the molar regions of the human mandible: a cadaveric study. Okajimas Folia Anat Jpn. 2005 Nov;82(3):95-101.

[15] D .Denio, M. Torabinejad, LK. Bakland. Anatomical relationship of the mandibular canal to its surrounding structures in mature mandibles. J Endod. Apr 1992;18(4):161-5.

[16] MH Levine, AL Goddard, TB Dodson. Inferior alveolar nerve canal position: a clinical and radiographic study. J Oral Maxillofac Surg. 2007 Mar;65(3):470-4

[17] H.Watanabe, M .MohammadAbdul, T.Kurabayashi, H.Aoki. Mandible size and morphology determined with CT on a premise of dental implant operation. Surg Radiol Anat. 2009. 